\title{
Towards the deployment of customer orientation: A case study in third-party logistics
}

\begin{abstract}
Customer orientation concerns the degree to which an organisation focuses on customers, recognises their desires and places meeting their needs as a first priority. As managing the needs of individual customers in supply chains become increasingly important, logistics companies have been recognising customer orientation as a critical aspect of their success. This study explores some of the challenges in the deployment of customeroriented logistics systems and argues that the so-called product intelligence model can provide an approach for developing such systems. Using an industrial case study, in this paper we examine customer orientation for a third-party logistics provider by examining both the development of information systems that enable the offering of flexible logistics offerings to the end customer and the impact of providing these offerings on a company's performance. We conclude with a set of functionalities required by information systems of logistics providers that wish to enhance customer orientation in their offerings

Keywords: customer-orientation, product intelligence, logistics, flexibility
\end{abstract}

\section{Introduction}

Due to the emerging importance of managing the needs of individual customers in supply chains, logistics companies have been increasingly recognising customer orientation as a critical success factor [1, 2, 3, 4]. Logistics companies and retailers alike aim to offer more customer-oriented logistics services by offering information systems that can support customer-orientation in logistics and its impact on existing operations and systems. We argue that the so-called product intelligence model [8, 9] for logically linking data and rules to a product, provides a suitable approach for the deployment of customer-oriented logistics which is often difficult to deploy with today's systems.

In particular, this study focuses on logistics offerings which allow the customer to flexibly intervene while his order is being processed. The development of these offerings are studied in detail via an in-depth third-party logistics case study, the aim of which is the examination of the challenges associated with the introduction of the offerings and their impact of performance. Besides analysing a specific industrial case, this study aims to contribute more generally to the functionalities required by information systems that wish to enhance customer orientation, towards their actual deployment. It also contributes to the product intelligence literature by further exploring its role for enhancing the customer-provider interaction.

Preprint submitted to Computers in Industry

October 16, 2018 
This paper is organised as follows. In Section 2 we present the main characteristics of a customer-oriented logistics system and we explore how companies achieve such characteristics today. In Section 3 we introduce a procedure for the development of an information model for customer-oriented logistics and we discuss the role of product intelligence in enabling the model. An industrial case study with an e-fulfilment company is presented in Section 4 which investigates the development of a customer-oriented logistics system, analyses the changes required in order for a conventional system to offer customer orientation and the impact on key performance measures.

\section{Background}

In this section, we aim to identify the key challenges towards developing customer-orientation in logistics by analysing the relevant literature and conducting a set of exploratory case studies. We also review the use of the product intelligence approach in logistics.

\subsection{Systems Supporting Customer-orientation in Logistics}

There are three main factors affecting the level of customer orientation in a logistics supply chain (and hence the level achieved by its member companies) [1: customer-closeness, customer-accessibility and customer-flexibility. Each of these factors impacts the core logistics operations of an organisation, i.e. inventory, transport and order management. Here, we focus our attention on the information systems required to support customer orientation and we identify requirements for an information system to support customeroriented logistics services. The characteristics are grouped by factors affecting customer orientation [1] and they draw directly from requirements for customer orientation presented in [4]:

- customer-closeness:

c1. represent the customer needs linked to an order,

c2. understand and perceive the customers' changing needs and requests over time,

c3. allow the customer to express his new preferences;

- customer-accessibility:

a1. collect order-level information regarding a customer's multiple requirements,

a2. monitor/track the progress of the order, even when the order passes through multiple organisations.

a3. allow customers to access information that is critical in fulfilling their multiple requirements;

- customer-flexibility:

f1. respond quickly to changing customer needs,

f2. influence the choice between different options affecting the order when such a choice needs to be made. 


\subsection{Customer Orientation in Conventional Logistics Systems}

Table 1: Conventional logistics systems fulfilling requirements of customer-orientation

\begin{tabular}{|c|c|c|c|}
\hline \multicolumn{2}{|c|}{ Customer-orientation } & \multirow[b]{2}{*}{$\begin{array}{l}\text { Extent addressed by conventional } \\
\text { systems }\end{array}$} & \multirow[b]{2}{*}{ Limitations of conventional systems } \\
\hline Aspects & Req & & \\
\hline \multirow[t]{3}{*}{ Closeness } & $c 1$ & $\begin{array}{l}\text { Orders associated with customer's ini- } \\
\text { tial choices regarding logistics services }\end{array}$ & $\begin{array}{l}\text { Orders are not necessarily linked with cus- } \\
\text { tomer's needs }\end{array}$ \\
\hline & $c^{2}$ & $\begin{array}{l}\text { Organisations understand new needs } \\
\text { based on the requests received }\end{array}$ & $\begin{array}{l}\text { New customer needs are not always translated } \\
\text { into new requests made by the customer }\end{array}$ \\
\hline & c3 & $\begin{array}{l}\text { Available up to a certain point of time } \\
\text { and for specific order characteristics }\end{array}$ & $\begin{array}{l}\text { Changes are time-dependent or require direct } \\
\text { communication }\end{array}$ \\
\hline \multirow[t]{3}{*}{ Accessibility } & $a 1$ & $\begin{array}{l}\text { Information provided relates to current } \\
\text { order status, possibly delivery time }\end{array}$ & $\begin{array}{l}\text { Orders hard to be tracked by the customer } \\
\text { since each company provides its own system }\end{array}$ \\
\hline & $a 2$ & An order is tracked at check points & $\begin{array}{l}\text { Real-time visibility is not available. Harder } \\
\text { when order passes through multiple companies }\end{array}$ \\
\hline & a3 & $\begin{array}{l}\text { Order-level information often captured } \\
\text { by the company }\end{array}$ & $\begin{array}{l}\text { Internal operations not entirely visible to the } \\
\text { customer }\end{array}$ \\
\hline \multirow[t]{2}{*}{ Flexibility } & $f 1$ & $\begin{array}{l}\text { Some changes allowed depending on } \\
\text { the status of the order }\end{array}$ & $\begin{array}{l}\text { Only limited options are given to the customer } \\
\text { or no options at all }\end{array}$ \\
\hline & f2 & $\begin{array}{l}\text { Ad-hoc solutions possible in certain } \\
\text { cases }\end{array}$ & $\begin{array}{l}\text { It requires the customer to contact the } \\
\text { provider and negotiate }\end{array}$ \\
\hline
\end{tabular}

Table 1 illustrates that conventional logistics systems are capable of providing a high-quality level of information associated with a customer's order and monitor their status during logistics operations. Companies understand the importance of accessibility and closeness; systems that can support these aspects have already been developed. For example, many last-mile logistics companies offer tracking services for free and many retailers provide inventory visibility via their web-sites. From a customer's perspective, the main limitation of existing systems appears when an order moves among multiple organisations, e.g. from a retailer to an order fulfilment company and then to a transportation provider. Similarly, customers find it 
hard to track multiple orders when they are required to use the different tracking systems of each logistics provider. Another limitation concerns the visibility provided for internal logistics operations, such as the status of the preparation of an order in a warehouse.

A key limitation of conventional systems however, relates to the limited flexibility available to a customer to $a$ ) express his new needs and $b$ ) change the details of his orders once placed. Conventional logistics systems do not normally allow changes on placed orders or only allow until a specified point of time, which depends on operational limitations [7, 10. Moreover, changes on placed orders normally require human-to-human interaction via phone calls and e-mails [11, 12].

These limitations are depicted in Figure 1 and can be summarised in the following:

1. Logistics services cannot be fully customised to a customer's needs.

2. When available, tracking information of a single order is stored in different information systems used by logistics providers.

3. Cancellations and amendments are only allowed in certain cases depending on the operational plans of the logistics provider.

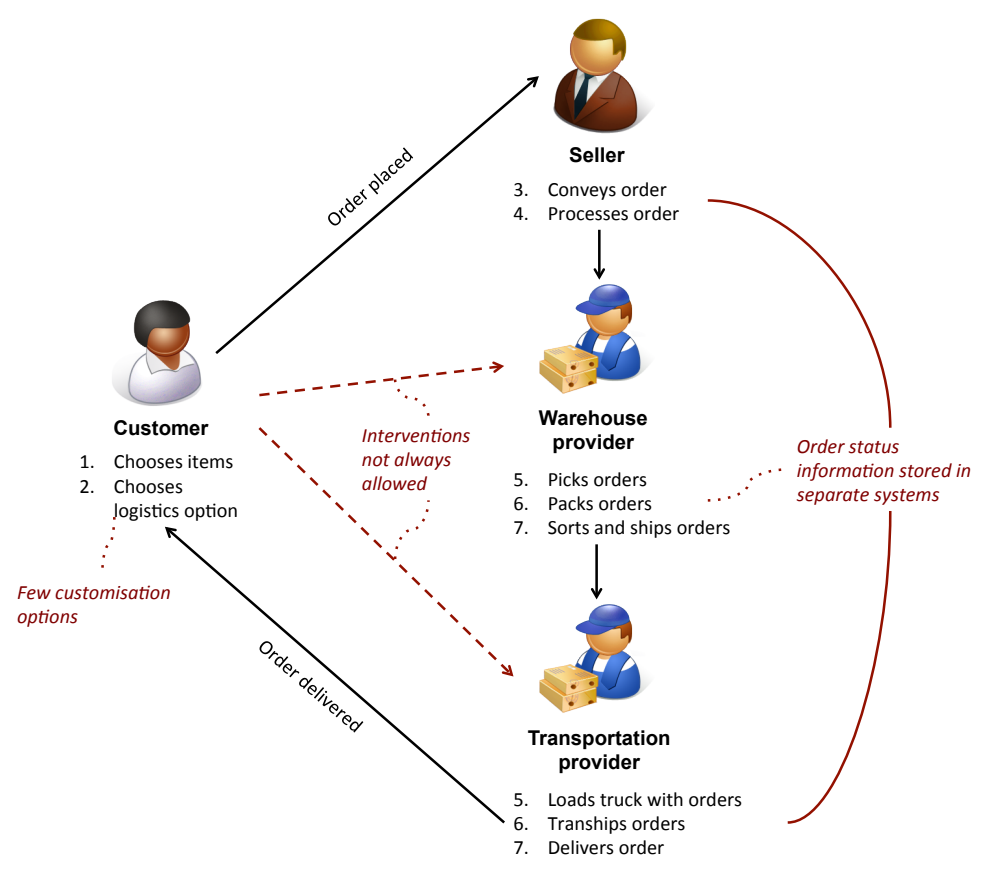

Figure 1: Limitations of conventional logistics systems for supporting customer orientation

We focus on how these limitations can be addressed by using the so-called product intelligence concepts to develop a more customer-oriented approach in the next section. We firstly, however, provide a brief review of the product intelligence paradigm and where it has been used. 


\subsection{Product Intelligence in Logistics}

In an industrial context, an intelligent product refers to a physical order or product instance that is linked to information and rules governing the way it is intended to be made, stored or transported that enable the product to support or influence these operations $[9,13,8$. For their implementation, intelligent products require digital elements (for information storage and decision support) — such as software agents [14, 15] to be connected to physical products (or orders), via means such as RFID, bluetooth, Wifi, QR, automated ID systems [16, 17, 18, 19, 20]. The paradigm is aligned with cyber-physical systems and aims to improve the responsiveness, flexibility and reconfigurability of industrial systems [21, 22, 23, 24]. Numerous studies studies have been made on the application of product intelligence in industrial systems, e.g. 25, 18, 26, and the interested reader is referred to these for more detailed information.

An intelligent product needs to have part or all of the following five characteristics $[\underline{8}$ :

1. Possesses a unique identity

2. Is capable of communicating effectively with its environment

3. Can retain or store data about itself

4. Deploys a language to display its features, production requirements etc.

5. Is capable of participating in or making decisions relevant to its own destiny

In logistics in particular, the role and potential benefits of product intelligence has been examined in different logistics operations including road-based transportation [27, 11, cross-docking [28, intermodal for the development of tracking systems used by courier companies [37.

\section{Customer-Oriented Logistics Using Product Intelligence}

In this section we discuss product intelligence as a potential enabler of customer-oriented logistics. We begin by proposing an information model for the customer-oriented order and we then explain the connection 


\subsection{An Information Model for a Customer-Oriented Order}

In this section, we describe a step-by-step development of an information model that enables customeroriented (C-O) features for an order and its links to a provider's system. In some ways this development mirrors developments of so-called 'digital twins' used in manufacturing and logistics [38, 39].

1. Establish a customer-oriented order template: What are the characteristics of an order as it is perceived by the customer? Besides its contents, an order is also likely to include a delivery option (e.g. speed, date), a delivery address and an alternative, value-added services (e.g. gift bag), payment details. For a customer-oriented order, it is important for the customer to be able to express his individual needs and preferences in case of a disruption.

2. Model the life-cycle of an order: What are the different stages an order has to go through from its placement to delivery (or even to its return)? Typically, a customer order will be part of one or more logistics orders (in the retailer), warehouse orders, picking, packing and shipping batches (in a warehouse), shipments and transshipments (during transportation). Also, what is the information needed for each stage?

3. Establish tracking and control of a customer order: In this step, the customer has access to a platform that allows him to track his order during its complete life-cycle from a single place. More importantly, using the platform, the customer can control and/or influence his order if needed, e.g. due to a change in his needs. Control can be done manually (a customer chooses among available options) or automatically (an option is chosen based on predefined customer preferences).

These steps develop the customer-oriented information model and a final step establishes links to provider information systems.

4. Create interfaces between customer order information model and providers' ordering, inventory and delivery systems: In order for customer orders to be fulfilled, they need to be processed by the information and operational systems of sellers and logistics providers. In this step, the necessary interfaces between the customer order and these systems are developed. Notice that these interfaces should allow a continuous interaction between the order and the systems for two reasons: a) the status of an order during its life-cycle will be more effectively tracked, and $b$ ) the details of an order might change during its life-cycle and these changes might require different processing from the systems.

The development of the information model and its links to provider information system for a customeroriented order is graphically illustrated in Figure 2 which shows the different steps a customer-oriented order goes through before and during its execution as well as its interactions with the provider's systems and templates. 


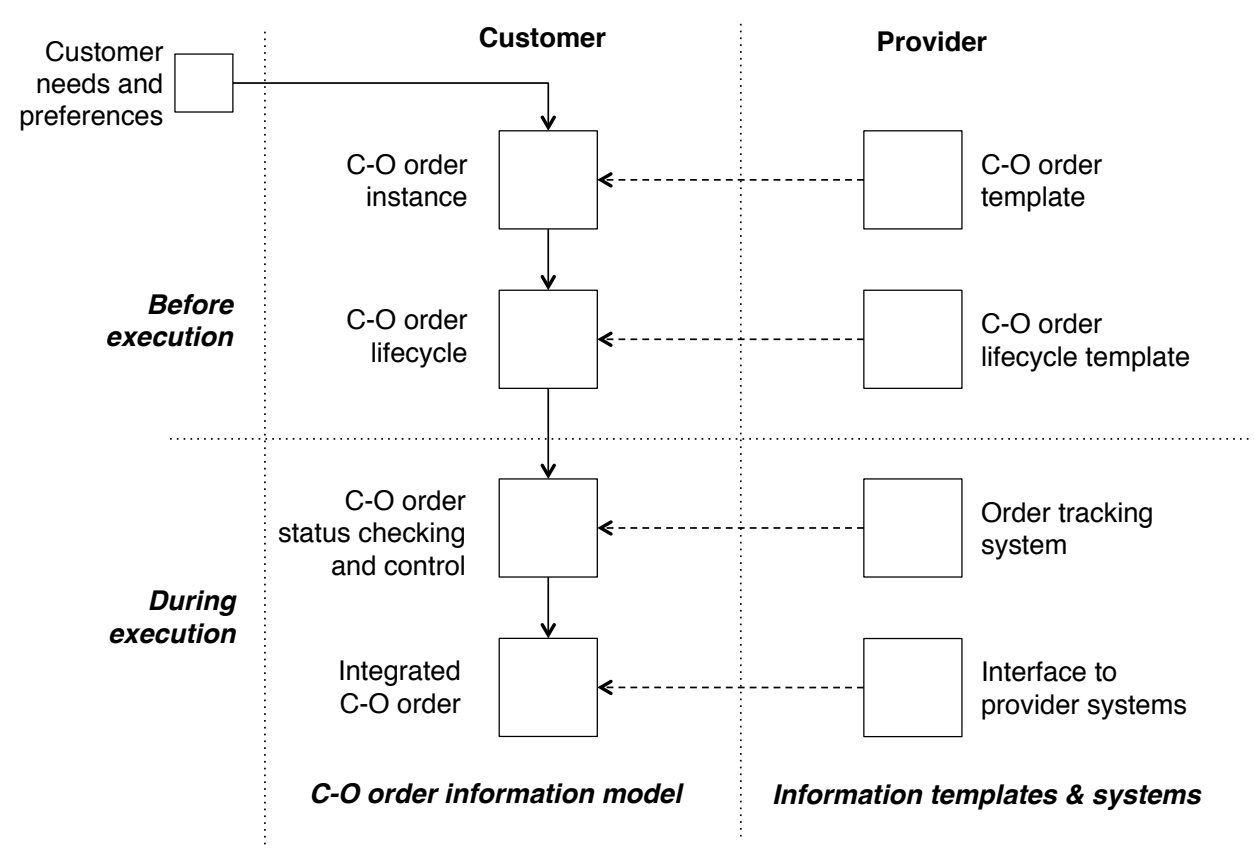

Figure 2: Procedure for developing an information model for customer-oriented order

\subsection{Deploying Customer-oriented Logistics with Product Intelligence}

The main benefit of introducing product intelligence into a logistics information system compared to 
Table 2: The role of product intelligence in Customer-oriented logistics

\begin{tabular}{|c|c|c|c|}
\hline \multirow{2}{*}{$\begin{array}{l}\text { Product Intelligence } \\
\text { characteristics }\end{array}$} & \multicolumn{3}{|c|}{ System capabilities for customer-oriented logistics } \\
\hline & Closeness & Accessibility & Flexibility \\
\hline $\begin{array}{l}\text { Possess a unique iden- } \\
\text { tity }\end{array}$ & $\begin{array}{l}\text { Link to the customer } \\
\text { needs associated to the } \\
\text { order }\end{array}$ & $\begin{array}{l}\text { Track the order in multi- } \\
\text { ple organisations }\end{array}$ & \\
\hline $\begin{array}{l}\text { Capable of communicat- } \\
\text { ing effectively with envi- } \\
\text { ronment }\end{array}$ & $\begin{array}{l}\text { Understand and perceive } \\
\text { customer's changing } \\
\text { needs and requests over } \\
\text { time }\end{array}$ & $\begin{array}{l}\text { Collect order-level infor- } \\
\text { mation regarding a cus- } \\
\text { tomer's multiple require- } \\
\text { ments }\end{array}$ & \\
\hline $\begin{array}{l}\text { Retain or store data } \\
\text { about }\end{array}$ & & $\begin{array}{l}\text { Monitor/Track the } \\
\text { progress of the order }\end{array}$ & \\
\hline $\begin{array}{l}\text { Deploy a language to } \\
\text { display features, pro- } \\
\text { duction requirements } \\
\text { etc. }\end{array}$ & $\begin{array}{l}\text { Express the preferences } \\
\text { of the customer }\end{array}$ & $\begin{array}{l}\text { Allow customers to access } \\
\text { information that is criti- } \\
\text { cal in fulfilling their needs }\end{array}$ & $\begin{array}{l}\text { Respond to changing cus- } \\
\text { tomer needs }\end{array}$ \\
\hline $\begin{array}{l}\text { Capable of participating } \\
\text { in or making decisions } \\
\text { relevant to own destiny }\end{array}$ & & & $\begin{array}{l}\text { Influence the choice be- } \\
\text { tween different options } \\
\text { affecting the order when } \\
\text { such a choice needs to be } \\
\text { made }\end{array}$ \\
\hline
\end{tabular}

conventional ones relates to the changes a customer can make to his orders (Step 3 at C-O Information Model Procedure). By deploying a language to communicate with its environment, an intelligent product enables the customer to express his changing preferences and needs and the provider to respond to them effectively. Therefore, using a product intelligence enabled system a customer can amend the details of his order, such as its delivery time, after its placement and the underlying information adapts to manage the change. Furthermore, by using AI-based software that allows an order to influence decisions, the customer can influence the choice between different options affecting the order, such as the way it will be stored, prepared or transported. Finally, we note that a product intelligence enabled system can also be partially or even fully automated. Instead of a customer keeping track of the status of his order and making decisions accordingly, he can define rules regarding the handling of his order under certain circumstances. In this way, new decisions can be automatically triggered in the system once an order enters a certain state such as for example in [40, 33, 41].

Last but not least, a product intelligence approach can enable the easier development of interfaces between a customer order and the provider's systems (Step 4 at C-O Information Model Procedure). This is due to the fact that, in a product intelligence approach, the decision making software agents associated with 
a product or order can easily communicate with the resources available at a provider's system, (which can also be represented by software agents themselves) and are capable of managing internal operations [13, 33]. Existing reference architectures from holonic manufacturing control [42, 43, 44, 45, 46] can be used for the implementation of the actual interfaces between a customer order and the providers' resources and products, after the necessary adaptation to cover the needs of logistics operations (e.g. a physical product is unlikely to require transformation in logistics as it is often the case in manufacturing).

A simple example that illustrates the result from applying the suggested procedure of the previous section in a logistics scenario (using product intelligence) is depicted in Figure 3 In this scenario a customer is ordering several items as part of a single order. Once the customer order is received by the seller, it generates an intelligent software agent to accompany it through preparation and transportation. In this way, agents collect information about the order status that can then share with the customers via on-line tracking systems, thus offering visibility of the internal order processing, warehousing and transportation operations. At the same time, they provide a platform for the customers to express their preferences.

Once a customer decides to amend the details of his order by adding more products to it or by changing the due date (after the order has been placed), the order agent is responsible for taking appropriate action depending on the order status at the time the amendment took place. In this example, the pick-list of a human picker needs to be dynamically updated in order to take into account the new item requested by the customer. This is decided after the order agent interacts with the warehousing system and negotiates with the corresponding picker agent about the inclusion of the new item in the existing pick list. The transportation option is also required to change to satisfy the new customer requirement regarding the delivery date. This is decided after evaluating the different transportation options the courier can offer at the time of request.

Figure 3 illustrates the way in which the proposed customer-oriented information model supplements rather than replaces a logistics provider information systems environment, substantially altering the way that environment interfaces to the customer. It also brings up a two key issues in adopting an intelligent product approach in practice. Firstly, the need to develop the necessary interfaces with existing warehouse and transportation management systems already in use by the different logistics providers an order interacts with during its life-cycle. This is indeed an important interoperability challenge that has been identified by various researchers in the past [47, 48, 49, 26]. As indicated in Figure 3, a potential solution for this issue is the usage of software agents (e.g. courier, picker, retailer) that represent different actors as it has been shown in other logistics contexts [34, 50. Secondly, the impact of allowing changes of customer orders to existing operations. This impact is twofold: firstly operations might need to be redesigned to be able to accommodate customer changes and secondly the overall performance of an operation might be affected while trying to accommodate a customer change (e.g. by affecting other customer orders). We will investigate both issues in the case study that follows. 


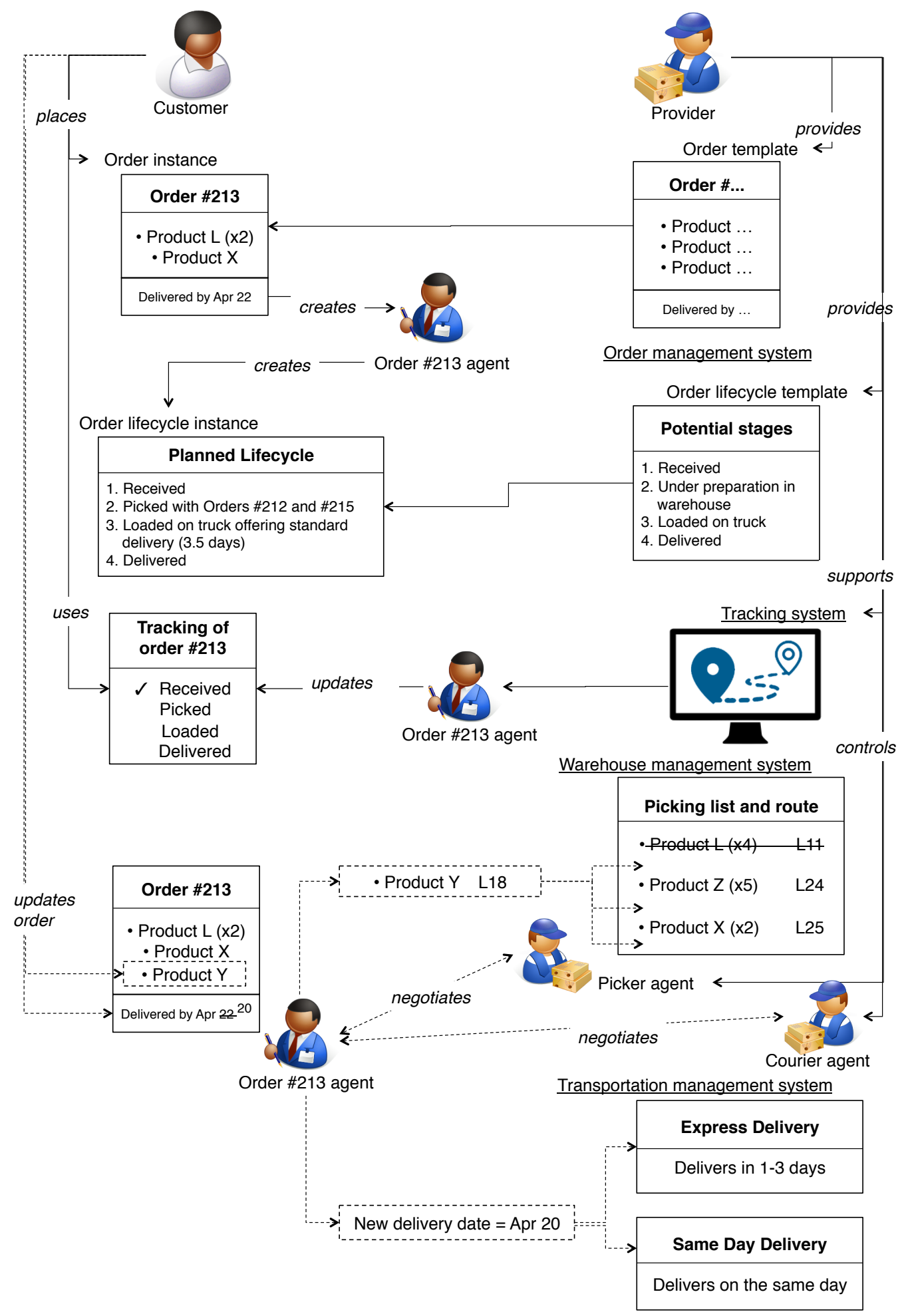

Figure 3: Example of supplementing provider information model with customer-oriented information 


\section{Case Study}

In this section we investigate implementation challenges of customer-oriented logistics via an in-depth case study with a third-party logistics company. The aims of this study were:

1. to explore how customer-oriented information can be embedded within the company's logistics systems (order management and warehouse management systems);

2. to determine how to adapt or extend the existing logistics system in order to offer customer orientation;

3. to evaluate the impact of customer orientation on provider performance.

Referring to Section 2.2, Table 1 we focused this case study on the flexibility aspect of customer orientation as logistics flexibility has been shown to impact customer satisfaction [51, 52. More specifically, we explored the implementation of logistics offerings that allow customers to amend the details of their orders after their placement (i.e. flexible logistics offerings); offerings that are not widely offered with today's systems but are clearly an important aspect of customer orientation. At the same time, enabling changes to delivery plans appears to be an important element of flexibility in other functions supported by industrial systems such as in manufacturing [53].

\subsection{Problem Description}

The case company is an e-commerce and mail order fulfilment warehouse company. The company acts as a third-party logistics operator. The company stores, picks, packs and dispatches goods to end-customers on behalf of their clients, the on-line retailers. The company offers customer accessibility via in-warehouse tracking and via links with courier tracking systems but was interested in determining under which circumstances increased levels of customer intervention would not necessarily disrupt regular operations.

In this study, we considered the case where the end-customer requests order modifications (via the retailer client). Modifications normally refer to a change in the delivery date or address of an order, a change in the contents of an order (product types and/or number of product instances) or, less often, the cancellation of an order. More specifically, we investigated the possibility of allowing end-customers to directly change the delivery option (and thus the delivery date) of an order at any point of time before the order is handed to a courier. At a trial stage, we investigated providing this offering to one of the company's big clients that counted for more than $15 \%$ of all orders placed.

\subsection{Developing the Customer-Oriented Logistics Solution}

In this section, we follow the four-step procedure presented in Section 3.1 to illustrate the solution (developed for the case study company) to enable flexible logistics offerings.

1. C-O order template: A customer order (consisting of items to be delivered to a (home) address) typically uses one of two options: $a$ ) guaranteed next day delivery using a courier service or $b$ ) priority 
delivery using postal services. In this case study, we consider a third possibility $c$ ) that the end-customer changes the order time some time after the order is placed.

2. Life-cycle model: From the perspective of the warehousing company, the life-cycle of an order begins when it is receiveed and ends with its despatch to the end-customer. The different states that a customer order goes through are shown in Figure 4 using a Petri Net diagram.

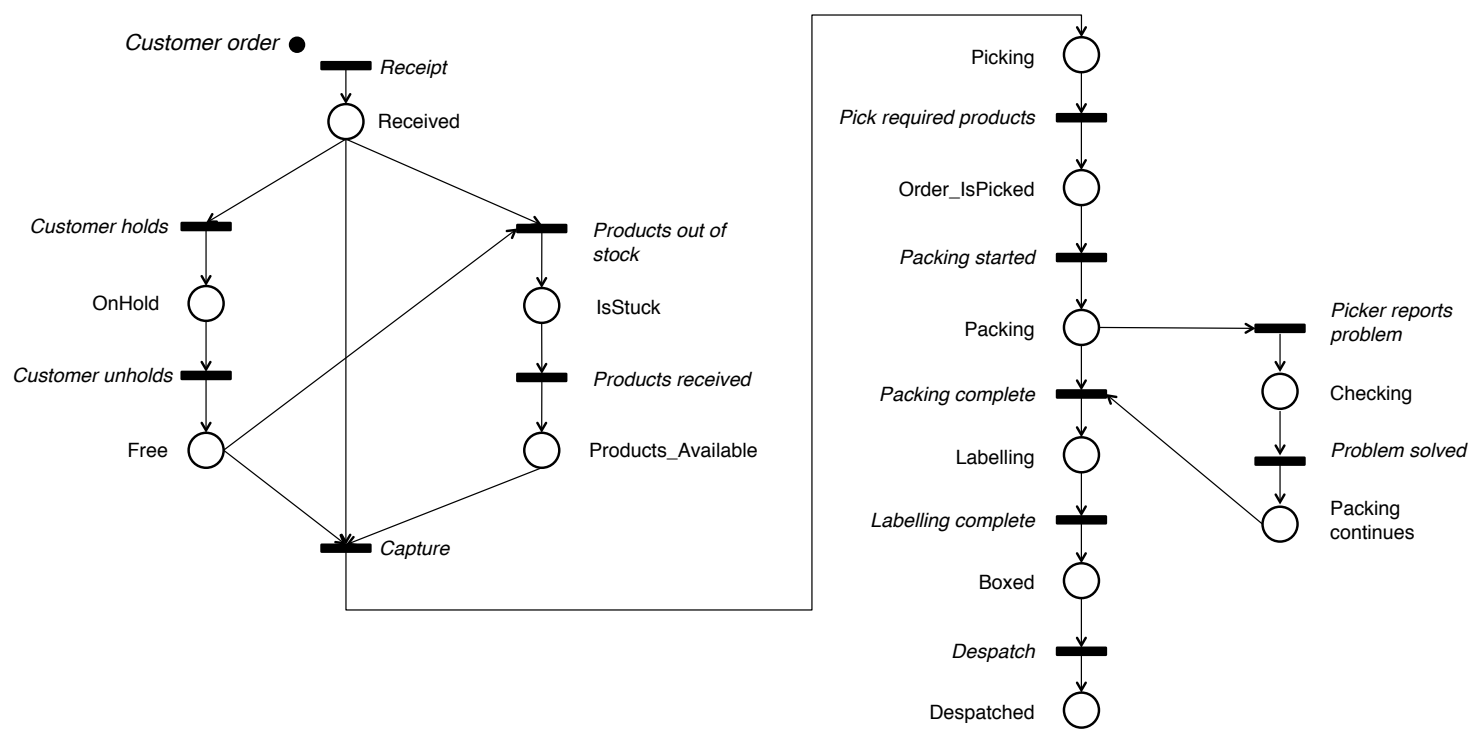

Figure 4: Petri Net for customer order

3. Tracking and control: The company offered an online platform that customers can use to check the status of their orders, as well as providing links to courier tracking systems. In a flexible logistics offering, end-customers should be able to use this platform to also control their orders.

4. Order-Provider interface: In order to enable order modifications at any point of time, three cases are identified depending on the status of the order at the time of request.

(a) Pref-pick modifications: If an order has not been picked by the time of the request, the company's client can put an order "on-hold" and make the appropriate changes via an on-line platform.

(b) Pre-labelled modifications: If at the time a request is received, the associated order has not been labelled, the company can change the delivery priority for this particular order (after modifying their IT systems accordingly). In this way, the order will be packed and labelled accordingly by a human operator when it reaches the packing stage. However, this is likely to slow down orders with lower priority.

(c) Post-labelled modifications: If the order has been labelled at the time of request, the order has to be located in the warehouse and then repacked and relabelled. This is a costly process. Firstly, it is likely that the order has to be relabelled which might require additional packaging material 
to be used. Secondly, locating an order in the warehouse can be very time consuming, especially in cases when an order has already been placed in a pile of boxed orders, ready to be despatched.

In order to demonstrate the implementation of the above flexible logistics offerings, a simulation model representing the company's operations was used. The simulation model was developed following the three steps defined by [54]. Firstly, an assumptions document that describes how the system works relative to the particular issues that the model is to address was created following observations of the warehouse operations

\subsection{Provider Challenges for Implementation}

Following detailed assessment with the case company, we now examine the impact of implementing a flexible logistics offering in conjunction with the third-party logistics provider's operational and IT systems. This is important as it affects the cost to the company to re-develop their existing systems towards a 295 customer-oriented system.

${ }^{1}$ https://www.simio.com/index.php 
a) Operational changes:

- For requests placed up to the point when an order is labelled (i.e. event 'Labelling Complete' in Figure (4), the existing operations can remain the same. This is because up to the point of labelling, the operations are the same for all orders regardless of their delivery option.

- For requests placed after an order is labelled, an extra process needs to be implemented. This process will a) allow a human operator to be notified when a new request is received, $b$ ) guide him in the warehouse in order to locate the boxed order that needs to be relabelled, $c$ ) allow him to relabel and sort the boxed order in the appropriate sorting bin.

b) Changes to IT systems:

- The provider gives access to tracking information of an order in the warehouse to the end-customer. Although this was offered by the case company, this is not common among logistics providers.

- A client needs to be given the option to modify the delivery option via the order management system (provided the order has not left the warehouse).

- If an order has not been assigned to a pick tour when a request for modification is placed, the warehouse management system should automatically modify the priority of the order to reflect the new delivery option.

- If an order has not been labelled when a request for modification is placed, the warehouse management system should automatically modify its delivery option, and then print the appropriate label with the new delivery details and point to the human operator the necessary packaging at the packing stage.

- If an order has been labelled and sorted when a request for modification is placed, the warehouse management system should notify an operator about the new request and point him to the physical location of the package in the warehouse.

In this case study only small changes were identified for delivering a flexible logistics offering because the current information systems used by the company have been developed on an order-level basis. Each order has its own data profile which is updated every time the order is processed, thus closely following the requirements of the customer-oriented information model (see 1).

Finally, we comment that the flexible logistics offering examined in this study focused on one type of modification. However, there are many ways to further enhance customer orientation by extending its flexible logistics offering. In this case example, a logistics provider could also consider the following:

- Allow changes to delivery dates after an order has been despatched. This would require an agreement between the warehouse provider and the transportation company, as well as the connection of their systems in order to offer a seamless interface to the client. 
- Allow changes to the contents of an order. This would require changes to the information and operational systems, similar to those discussed above, but further, information systems that facilitate the logistics offering: about $0.6 \%$ fewer orders are despatched on the same day and it takes an order about 13.8 minutes longer on average before an order gets ready for despatch. The impact on these performance measures should be carefully evaluated in comparison to the expected increased revenue from making the offering available.

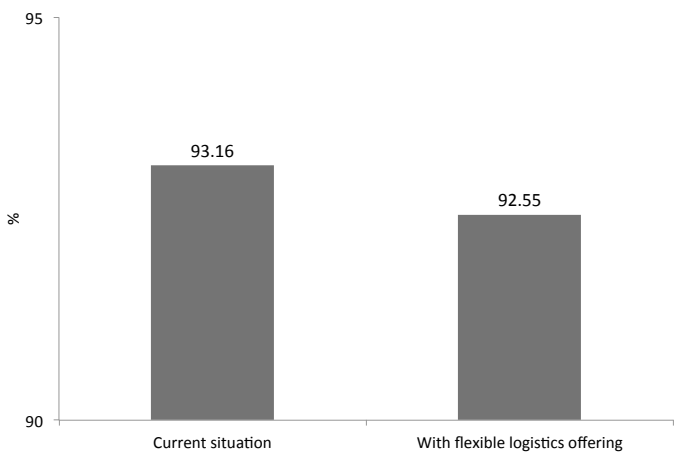

(a) Percentage of 'same-day-despatched' orders.

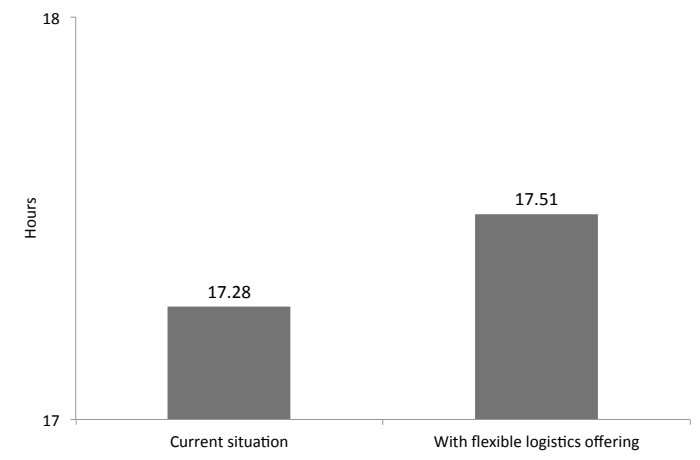

(b) Average total time until labelled.

Figure 5: Impact of introducing flexible logistics offering on warehouse performance. control of the company (although the company's pricing strategy can influence this). As the number of 
these orders increases (or decreases), the impact on performance is expected to change as well. We examine this issue by varying the probability that an order will require modification in the range $5 \%$ and $40 \%$. This translates to between 45 and 360 orders per month. Figure6 6 illustrates the impact of varying probabilities on the 'same-day-despatched orders' and the 'total time until labelled' measures ${ }^{2}$. As expected, the larger the number of orders requesting modifications, the more significant the impact of the flexible logistics offering. This observation should be expected on this business scenario, if one considers that the more time human operators spend on orders requiring special treatment, the less time they have to perform their normal tasks.

On the other hand, the introduction of a flexible logistics offering does not jeopardise overall performance. For example, from Figure 6 a, when there is a very high chance of requesting a change (i.e. 0.4 ), only $2 \%$ fewer orders are not despatched on the same day (from $93.16 \%$ to $91.17 \%$ ), and when half of these orders need modifications, the difference decreases by more than $50 \%$ (from $2 \%$ to $0.83 \%$ ). Similarly Figure6 illustrates the extra time needed for each order until it is labelled, which varies from an extra 0.11-0.91 hours when a flexible logistics offering is in place. Once again, even for a very high probability of modifications, each order will take, on average, about 55 minutes longer to complete compared to the total time needed currently (i.e. $5 \%$ increase). This indicates some resilience of the company's operations to the potential disruption imposed by frequent order modifications.

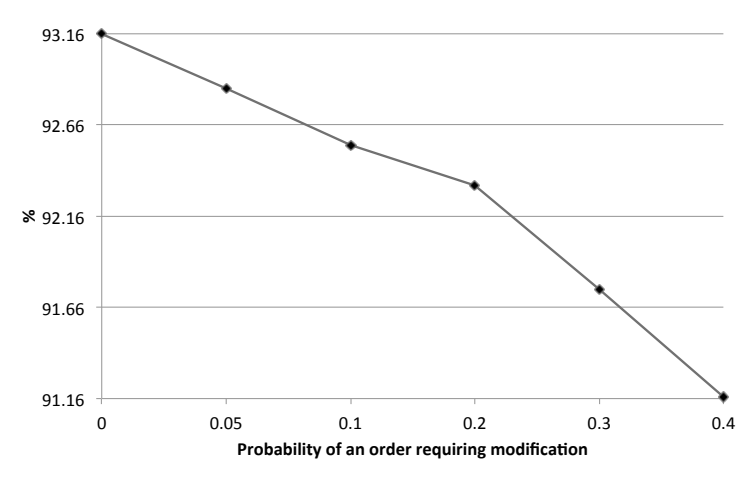

(a) Percentage of 'same-day-despatched' orders.

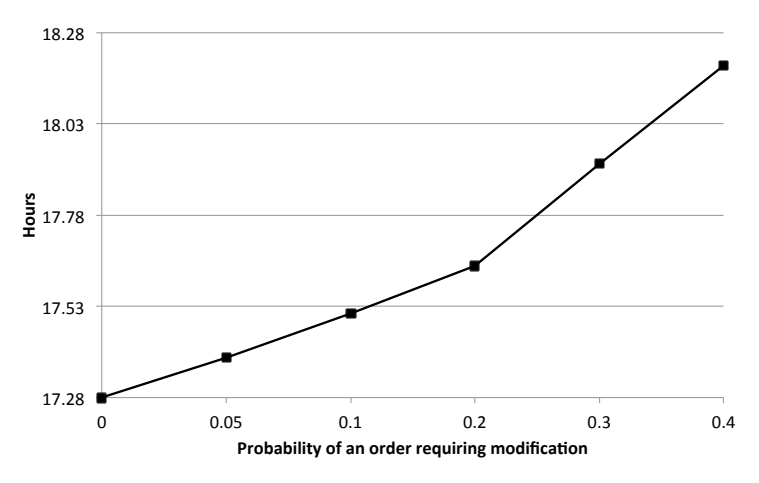

(b) Average total time until labelled.

Figure 6: Performance measures for varying probability of modifications.

To sum up, the overall performance of the warehouse operations for the case study company is only minimally affected by interventions to planned operations. This is due to the fact that customer requests for modifications require interventions to planned operations. These interventions can be costly either because they call for human resources who could be occupied elsewhere or due to extra material needed to reprocess an order.

\footnotetext{
${ }^{2}$ When this probability equals zero, no orders require modification and therefore the flexible logistics offering is not in use.
} 


\section{Conclusions}

In this paper, we examined the issue of supporting customer orientation in logistics by the introduction of a procedure for the development of an order information model. We believe that the key findings can be generalised to other logistics companies who wish to enhance their customer-oriented offerings, especially the flexibility aspects of them:

- Certain changes are required to operations and IT systems in order to allow and support customer interventions. These changes are likely to be of similar nature across logistics companies (especially e-commerce ones) as the order life-cycle remains — at a certain extend - similar.

- These changes have the potential to impact on the performance of the physical logistics operations. Even though some performance degradation occurs depending on the number of orders requiring modifications and their status at the time of request, this impact was shown to be minimal in the case studied.

- The product intelligence approach can be used as a suitable enabler for the implementation of the model, supplementing rather than replacing existing systems.

Even though this study focused on e-commerce fulfilment as an application example, we believe its findings are applicable to other logistics and manufacturing cases that experience similar order life-cycles and that face similar pressures with regard to offering greater flexibility. Such cases are most likely to be business-to-consumer cases as they need to handle the requirements of several different individual customers. In e-commerce in particular, we note that enhanced flexibility can be at odds with another emerging trend; that of speed. In cases where customers require very fast delivery times (see for example Amazon's 2-hour delivery scheme), the available time for changes and modifications is also significantly limited.

Finally, this study also identifies a set of functionalities that an information system should be able to deliver in order to provide a platform for the development of customer orientation. Luckily, some of these functionalities are already developed in industrial systems today. These functionalities can be summarised in the following:

1. allowing a customer to express order requirements before and after its placement,

2. allowing a customer to access data about the status of his orders and the possible ways to influence them,

3. translating new customer requests into operational changes and notifying human operators,

4. negotiating with the customer and/or other participating organisations (e.g. carriers, clients, thirdparty logistics providers) over the details of the logistics order (e.g. price, new delivery date). 


\section{Funding}

This study has been funded via the "Individual Assessment Scholarship Programme of the State Scholarship Foundation of Greece 2011-2012" using funds from the "Education and Lifelong Learning" Operational Programme of the European Social Fund (ESF) and the NSRF, 2007-2013.

\section{References}

[1] J. S. Jeong, P. Hong, Customer orientation and performance outcomes in supply chain management, Journal of Enterprise Information Management 20 (5) (2007) 578-594. doi:10.1108/ 17410390710823707 .

[2] Y. Tian, A. E. Ellinger, H. Chen, Third-party logistics provider customer orientation and customer firm logistics improvement in China, International Journal of Physical Distribution \& Logistics Management 40 (5) (2010) 356-376. doi:10.1108/09600031011052822.

[3] A. C. Lyons, A. E. C. Mondragon, F. Piller, R. Poler, Customer-Driven Supply Chains, Springer London, 2012. doi:10.1007/978-1-84628-876-0

[4] D. McFarlane, V. Giannikas, W. Lu, Intelligent logistics: Involving the customer, Computers in Industry 81 (2016) 105-115. doi:10.1016/j.compind.2015.10.002.

[5] UPS, Ups my choice, Available online at http://www.ups.com/mychoice/welcome.html. Accessed October 2017 (2017).

[6] FedEx, Fedex delivery manager, Available online at http://www.fedex.com/us/delivery/. Accessed October 2017 (2016).

[7] Tesco, Grocery online help, Available online at http://www.tesco.com/groceries/help/?rel=help. Accessed October 2017 (2017).

[8] C. Wong, D. McFarlane, A. Zaharudin, V. Agarwal, The intelligent product driven supply chain, in: IEEE International Conference on Systems, Man and Cybernetics, Vol. 4, 2002, p. 6.

[9] M. Kärkkäinen, J. Holmström, K. Främling, K. Artto, Intelligent products-a step towards a more 口 effective project delivery chain, Computers in Industry 50 (2) (2003) 141-151. doi:10.1016/ S0166-3615(02)00116-1.

[10] Amazon, Help and customer service, Available online at http://www . amazon.com/gp/help/customer/ display.html. Accessed February 2017 (2017).

[11] G. Meyer, P. Buijs, N. Szirbik, H. Wortmann, Intelligent products for enhancing the utilization of tracking technology in transportation, International Journal of Operations \& Production Management 34 (4) (2014) 1-1. 
[21] P. Leitao, N. Rodrigues, J. Barbosa, C. Turrin, A. Pagani, Intelligent products: The grace experience, 2015.05.001.

[22] T. Borangiu, S. Raileanu, T. Berger, D. Trentesaux, Switching mode control strategy in manufacturing

[12] M. van der Linden, B. van Scherpenzeel, Charlie Pappa: Connecting Ports project flyer (2014).

[13] D. McFarlane, S. Sarma, J. L. Chirn, C. Y. Wong, K. Ashton, Auto ID systems and intelligent manufacturing control, Engineering Applications of Artificial Intelligence 16 (4) (2003) 365-376. doi: 10.1016/S0952-1976(03)00077-0.

[14] K. Främling, T. Ala-Risku, M. Kärkkäinen, J. Holmström, Agent-based model for managing composite product information, Computers in Industry 57 (1) (2006) 72-81. doi:10.1016/j.compind.2005.04. 004

URL http://www.sciencedirect.com/science/article/pii/S0166361505000801

[15] P. Valckenaers, B. S. Germain, P. Verstraete, J. V. Belle, Hadeli, H. V. Brussel, Intelligent products: Agere versus Essere, Computers in Industry 60 (3) (2009) 217-228. doi:10.1016/j.compind.2008.12.008. URL http://www.sciencedirect.com/science/article/B6V2D-4VDSCRC-3/2/ 5bb91574f9544d078f12359f2025a088

[16] K. Främling, M. Harrison, J. Brusey, J. Petrow, Requirements on unique identifiers for managing product lifecycle information: comparison of alternative approaches, International Journal of Computer Integrated Manufacturing 20 (7) (2007) 715-726.

[17] X. Yang, P. Moore, S. K. Chong, Intelligent products: From lifecycle data acquisition to enabling product-related services, Computers in Industry 60 (3) (2009) 184-194. doi:10.1016/j.compind. 2008.12.009.

[18] D. Kiritsis, Closed-loop plm for intelligent products in the era of the internet of things, Computer-Aided Design 43 (5) (2011) 479-501. doi:10.1016/j.cad.2010.03.002

[19] A. Zouinkhi, E. Bajic, E. Rondeau, M. B. Gayed, N. Abdelkrim, Ambient intelligence: Awareness context application in industrial storage, Wireless Sensor Network 2011 (3) (2011) 134-145.

[20] P. Pujo, F. Ounnar, D. Power, S. Khader, Wireless holon network for job shop isoarchic control, Computers in Industry 83 (2016) 12-27. doi:10.1016/j.compind.2016.08.005 URL http://www.sciencedirect.com/science/article/pii/S0166361516301609 Control Engineering Practice 42 (2015) 95-105. doi:http://dx.doi.org/10.1016/j.conengprac. execution systems, International Journal of Production Research 53 (7) (2015) 1950-1963. 
[23] J.-F. Jimenez, A. Bekrar, D. Trentesaux, P. Leitao, A switching mechanism framework for optimal coupling of predictive scheduling and reactive control in manufacturing hybrid control architectures, International Journal of Production Research 54 (23) (2016) 7027-7042.

[24] F. Ounnar, P. Pujo, M. Hachicha, Y. Dubromelle, Study of an intelligent and multicriteria scheduling service, using academic benchmarks, International Journal of Computer Integrated Manufacturing 29 (11) (2016) 1166-1176. arXiv:https://doi.org/10.1080/0951192X.2015.1030696, doi: 10.1080/0951192X.2015.1030696. URL https://doi.org/10.1080/0951192X.2015.1030696

[25] G. G. Meyer, K. Främling, J. Holmström, Intelligent products: A survey, Computers in Industry 60 (3) (2009) 137-148. doi:10.1016/j.compind.2008.12.005.

[26] D. McFarlane, V. Giannikas, A. C. Wong, M. Harrison, Product intelligence in industrial control: Theory and practice, Annual Reviews in Control 37 (1) (2013) 69-88. doi:10.1016/j.arcontrol.2013.03. 003.

[27] R. Jedermann, W. Lang, The benefits of embedded intelligence: tasks and applications for ubiquitous computing in logistics, in: Proceedings of the 1st international conference on The internet of things, Springer-Verlag, Berlin, Heidelberg, 2008, pp. 105-122.

[28] J. Van Belle, B. Saint Germain, P. Valckenaers, H. Van Brussel, R. Bahtiar, D. Cattrysse, Intelligent products in the supply chain are merging logistic and manufacturing operations, in: 18th IFAC World Congress, Milano, Italy, 2011, pp. 1596-1601.

[29] V. Giannikas, D. McFarlane, Product intelligence in intermodal transportation: The dynamic routing problem, in: H.-J. Kreowski, B. Scholz-Reiter, K.-D. Thoben (Eds.), Dynamics in Logistics, Lecture Notes in Logistics, Springer Berlin Heidelberg, 2013, pp. 59-69.

[30] Y. Sallez, S. Pan, B. Montreuil, T. Berger, E. Ballot, On the activeness of intelligent physical internet containers, Computers in Industry 81 (2016) 96-104.

[31] V. Giannikas, W. Lu, D. McFarlane, J. Hyde, Product intelligence in warehouse management: A case study, in: V. Mařík, J. L. M. Lastra, P. Skobelev (Eds.), HOLOMAS 2013: 6th International Conference on Industrial Applications of Holonic and Multi-Agent Systems, Vol. 8062 of Lecture Notes in Computer Science, Springer Berlin Heidelberg, 2013, pp. 224-235.

[32] N. Tsamis, V. Giannikas, D. McFarlane, W. Lu, J. Strachan, Adaptive storage location assignment for warehouses using intelligent products, in: T. Borangiu, A. Thomas, D. Trentesaux (Eds.), Service Orientation in Holonic and Multi-agent Manufacturing, Vol. 594 of Studies in Computational Intelligence, Springer International Publishing, 2015, pp. 271-279. 
[33] G. G. Meyer, J. Wortmann, N. B. Szirbik, Production monitoring and control with intelligent products, International Journal of Production Research 49 (5) (2011) 1303-1317. doi:10.1080/00207543.2010.

[34] A. Brintrup, D. McFarlane, D. Ranasinghe, T. Sanchez Lopez, K. Owens, Will intelligent assets take off? Toward self-serving aircraft, IEEE Intelligent Systems 26 (3) (2011) 66-75. doi:10.1109/MIS.2009.89

[35] D. Trentesaux, B. Grabot, Y. Sallez, Intelligent products: A spinal column to handle information exchanges in supply chains, in: V. Prabhu, M. Taisch, D. Kiritsis (Eds.), Advances in Production Management Systems. Sustainable Production and Service Supply Chains, Vol. 415 of IFIP Advances in Information and Communication Technology, Springer Berlin Heidelberg, 2013, pp. 452-459.

[36] D. Trentesaux, A. Thomas, Product-driven control: a state of the art and future trends, in: 14th IFAC Symposium on Information Control Problems in Manufacturing, Bucharest, Romania, 2012.

[37] J. Holmström, R. Kajosaari, K. Främling, E. Langius, Roadmap to tracking based business and intelligent products, Computers in Industry 60 (3) (2009) 229-233. doi:10.1016/j.compind.2008.12.006.

[38] B. Schleich, N. Anwer, L. Mathieu, S. Wartzack, Shaping the digital twin for design and production engineering, CIRP Annals 66 (1) (2017) 141-144. doi:10.1016/j.cirp.2017.04.040.

[39] M. Vanderroost, P. Ragaert, J. Verwaeren, B. D. Meulenaer, B. D. Baets, F. Devlieghere, The digitization of a food packages life cycle: Existing and emerging computer systems in the logistics and post-logistics phase, Computers in Industry 87 (2017) 15-30. doi:10.1016/j.compind.2017.01.004

[40] Y. Sallez, T. Berger, D. Trentesaux, A stigmergic approach for dynamic routing of active products in fms, Computers in Industry 60 (3) (2009) 204-216. doi:10.1016/j.compind.2008.12.002.

[41] K. Främling, J. Holmström, J. Loukkola, J. Nyman, A. Kaustell, Sustainable PLM through intelligent 1. products, Engineering Applications of Artificial Intelligence 26 (2) (2013) 789-799. doi:10.1016/j. engappai.2012.08.012.

[42] H. V. Brussel, J. Wyns, P. Valckenaers, L. Bongaerts, P. Peeters, Reference architecture for holonic 口 manufacturing systems: Prosa, Computers in Industry 37 (3) (1998) 255-274. doi:10.1016/ S0166-3615(98)00102-X.

URL http://www.sciencedirect.com/science/article/pii/S016636159800102X

[43] P. Leitao, F. Restivo, ADACOR: A holonic architecture for agile and adaptive manufacturing control, Computers in Industry 57 (2) (2006) 121-130. doi:10.1016/j.compind.2005.05.005.

URL http://www.sciencedirect.com/science/article/pii/S0166361505001077 
[44] P. Pujo, N. Broissin, F. Ounnar, PROSIS: An isoarchic structure for hms control, Engineering Applications of Artificial Intelligence 22 (7) (2009) 1034-1045. doi:10.1016/j.engappai.2009.01.011.

[45] J. Barbosa, P. Leitao, E. Adam, D. Trentesaux, Dynamic self-organization in holonic multi-agent

口 manufacturing systems: The ADACOR evolution, Computers in Industry 66 (2015) 99-111. doi: 10.1016/j.compind.2014.10.011.

URL http://www.sciencedirect.com/science/article/pii/S0166361514001894

[46] C. Indriago, O. Cardin, N. Rakoto, P. Castagna, E. Chacon, H2cm: A holonic architecture for flexible hybrid control systems, Computers in Industry 77 (2016) 15-28. doi:10.1016/j.compind.2015.12. 005.

URL http://www. sciencedirect.com/science/article/pii/S0166361515300695

[47] J. Holmström, K. Främling, J. Tuomi, M. Kärkkäinen, T. Ala-Risku, Implementing collaboration process networks, The International Journal of Logistics Management 13 (2) (2002) 39-50.

[48] M. Kärkkäinen, T. Ala-Risku, K. Främling, The product centric approach: a solution to supply network information management problems?, Computers in Industry 52 (2) (2003) 147-159. doi:10.1016/S0166-3615(03)00086-1.

URL http://wWw.sciencedirect.com/science/article/B6V2D-4997YF6-1/2/ $6439 \mathrm{e} 249530581015785 f 9 a 04 d 8 d d c 59$

[49] K. Hribernik, L. Rabe, J. Schumacher, K. Thoben, The product avatar as a product-instance-centric information management concept, International Journal of Product Lifecycle Management 1 (4) (2006) $367-379$.

[50] P. J. Reaidy, A. Gunasekaran, A. Spalanzani, Bottom-up approach based on internet of things for order fulfillment in a collaborative warehousing environment, International Journal of Production Economics 159 (2015) 29-40.

[51] Q. Zhang, M. A. Vonderembse, J.-S. Lim, Logistics flexibility and its impact on customer satisfaction, International Journal of Logistics Management 16 (1) (2005) 71-95.

URL http://search. proquest. com/docview/235923367?accountid=9851

[52] H. Jafari, Logistics flexibility: a systematic review, International Journal of Productivity and Performance Management 64 (7) (2015) 947-970. doi:10.1108/IJPPM-05-2014-0069.

[53] N. Burger, M. Demartini, F. Tonelli, F. Bodendorf, C. Testa, Investigating flexibility as a performance 口 dimension of a manufacturing value modeling methodology (MVMM): A framework for identifying flexibility types in manufacturing systems, Procedia CIRP 63 (2017) 33-38, manufacturing Systems 4.0 
Proceedings of the 50th CIRP Conference on Manufacturing Systems. doi:10.1016/j.procir.2017. 03.343

URL http://www.sciencedirect.com/science/article/pii/S2212827117306534

[54] A. M. Law, Simulation Modeling \& Analysis, forth Edition, McGraw-Hill, New York, NY, 2007.

[55] W. Lu, D. McFarlane, V. Giannikas, Q. Zhang, An algorithm for dynamic order-picking in warehouse 565 operations, European Journal of Operational Research 248 (1) (2016) 107-122. doi:10.1016/j.ejor. 2015.06 .074

\section{Appendix A. Exploratory case studies information}

The semi-structured interviews used for the exploratory case studies of this research study were conducted using the following list of questions:

1. Explain what logistics operations you are responsible for in your organisation?

2. Do you normally place orders (as a customer) or receive requests for orders/logistics services?

3. If customer:

(a) Describe a typical order you normally place to your supplier/provider.

(b) Do you ever need to change the details of your orders after you place them? In which cases? Which details?

(c) How do you track the status of your order and the progress of your requests?

(d) What do you normally do in these cases (what process, who to contact, what information systems)

(e) Are you satisfied by this process? What would you like to be able to do instead?

(f) What do you think is the impact for not being able to change the details of your orders/for changing the details with the current process?

(g) Would you be happy to be given the opportunity to pay a fee to change the details of your placed orders?

4. If not customer:

(a) Describe a typical order customers normally place to you.

(b) What are the options offered to them regarding logistics operations?

(c) Do your customers ever need to change the details of their orders after they place them? In which cases? Which details?

(d) How do you get informed about these requests? 
(e) What do you normally do in these cases (what process, who to contact, what information systems)?

(f) How would you characterise this process (time-consuming, add-hoc, easy?). What would you like to be able to do instead?

(g) Do you think it is feasible to allow your customers to change the details of their orders at any point of time? What would it take to make this happen (changes in operations, information systems, processes)?

(h) What do you think is the impact for not allowing your customers to change the details of their orders at any point of time? Do you think they would be interested in having the opportunity to do so (perhaps after paying a fee)?

A summary of the interviewed organisations appears in Table A.3.

Table A.3: Companies participating in exploratory case studies

\begin{tabular}{llll}
\hline Actor & Industry & Systems discussed & Code name \\
\hline Customer/Shipper & Airline & OMS & Company A \\
& Aerospace and defence & OMS & Company B \\
Retailer & Grocery Stores & OMS, TMS, WMS & Company C \\
Fulfilment services provider & Online shopping & OMS, WMS & Company D \\
Logistics services provider & Transportation \& logistics & OMS, TMS & Company E \\
Courier services provider & Transportation \& logistics & OMS, TMS & Company F \\
\hline
\end{tabular}

\section{Appendix B. Simulation Development and Validation}

\section{Appendix B.1. Development}

For the development of the simulation model, various Simio elements were used as they are summarised in Table B.4. Figures B.7 and B.8 also illustrate the software environment developed in Simio.

\section{Appendix B.2. Validation}

Several components of the simulation model were quantitatively validated using data obtained from a simulation run of 1000 replications. In the experiment, the computer programme run for a calendar month for which operational data were collected from the company in November 2013. The runs used a warm-up period of 24 hours which were enough for a representative number of orders to enter the system before the first day of simulation. Table B.5 provides a comparison between the system's mean and the mean of the simulation output of a set of measures used for validation. The third and forth columns present the lower and upper bounds of a $95 \%$ confidence interval constructed around the system mean where applicable. As 


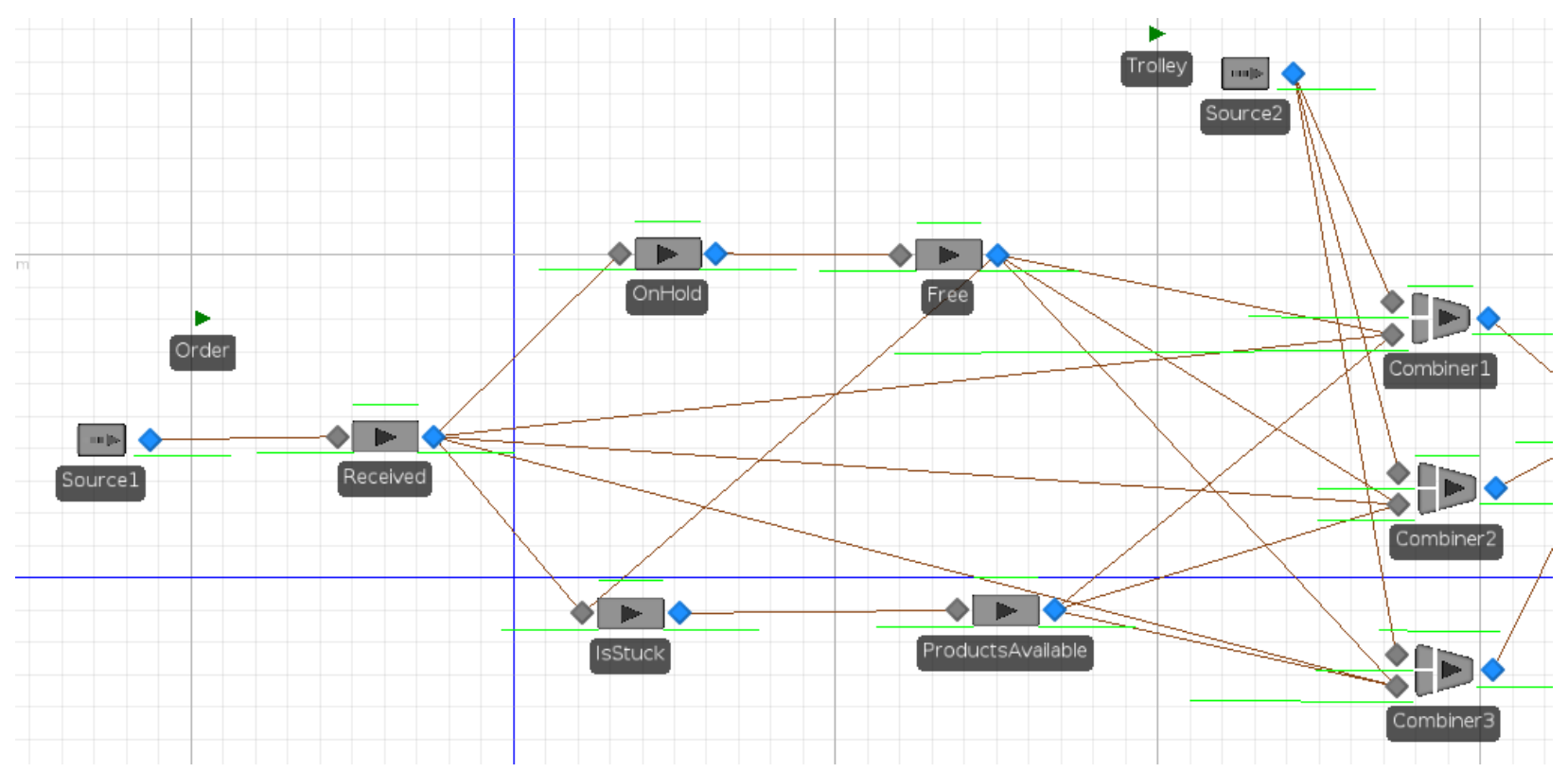

Figure B.7: Warehouse operations in simulation programme $(1 / 2)$

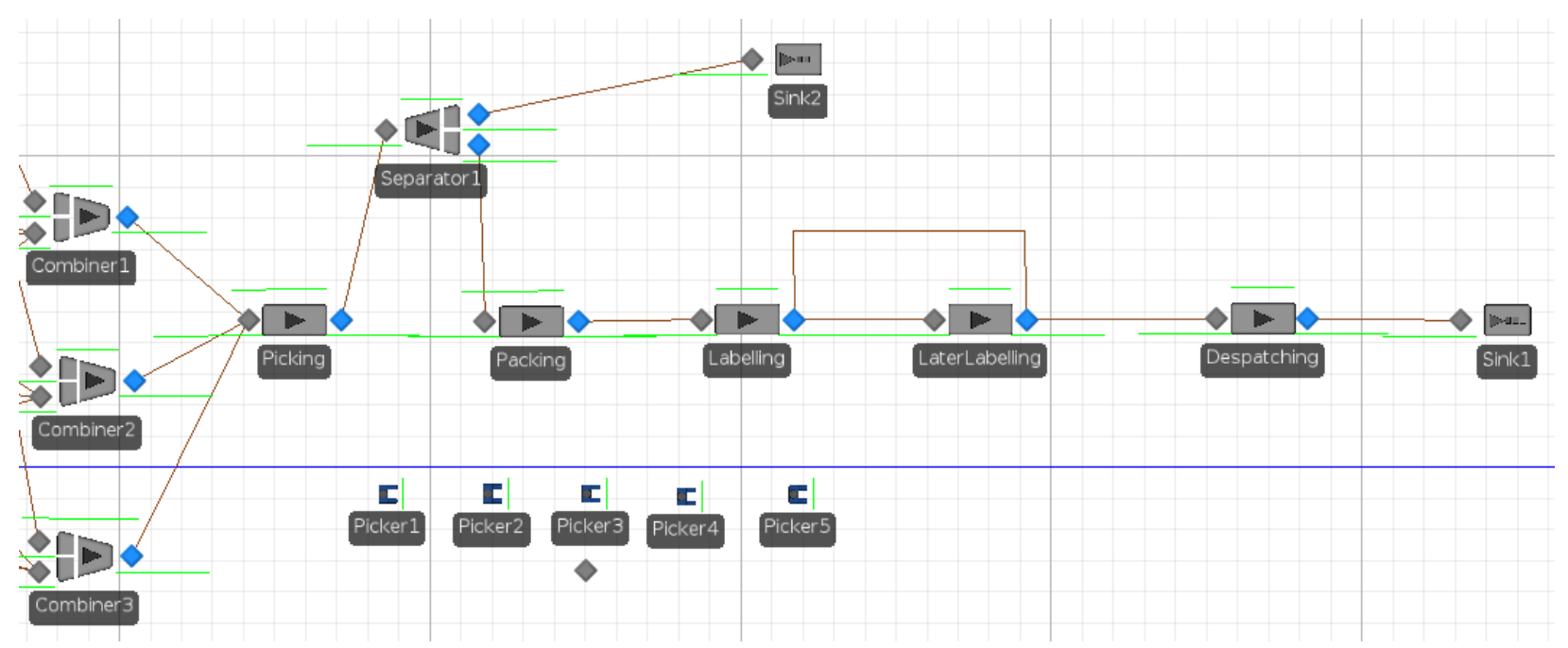

Figure B.8: Warehouse operations in simulation programme $(2 / 2$ 
Table B.4: Implementation details in the Simio programming environment

\begin{tabular}{|c|c|c|}
\hline $\begin{array}{l}\text { Warehouse operation ele- } \\
\text { ments }\end{array}$ & Simio elements & Comments \\
\hline Customer orders & Model entity & \\
\hline $\begin{array}{l}\text { Arrival of new orders and avail- } \\
\text { able trolleys }\end{array}$ & Source & $\begin{array}{l}\text { Orders arrive throughout a day using different } \\
\text { interarrival times in } 24 \text { different time slots. }\end{array}$ \\
\hline Picking trolleys & Parent model entity & \\
\hline $\begin{array}{l}\text { States (receiving, picking, la- } \\
\text { belling etc.) }\end{array}$ & Server & $\begin{array}{l}\text { Each server is available based on a work } \\
\text { schedule. }\end{array}$ \\
\hline $\begin{array}{l}\text { Assigning orders to picking } \\
\text { trolleys }\end{array}$ & Combiner & $\begin{array}{l}\text { Used to combine multiple member entities } \\
\text { (customer orders) together with a parent en- } \\
\text { tity (trolley). }\end{array}$ \\
\hline $\begin{array}{l}\text { Remove orders from picking } \\
\text { trolleys before packing }\end{array}$ & Separator & $\begin{array}{l}\text { Used to split a batched group of entities (trol- } \\
\text { ley) to the initial member entities (orders). }\end{array}$ \\
\hline $\begin{array}{l}\text { Customer order characteristics } \\
\text { (priority, size, etc.) }\end{array}$ & Model entity properties & \\
\hline Opearators & Workers & $\begin{array}{l}\text { Five workers are used, with different work } \\
\text { schedules. Workers are requested by servers } \\
\text { when there are orders waiting for processing. }\end{array}$ \\
\hline $\begin{array}{l}\text { Orders and used trolleys exit- } \\
\text { ing the system }\end{array}$ & Sink & \\
\hline
\end{tabular}

Table B.5 illustrates, the simulation outputs are very close to the system mean and inside the confidence interval.

Table B.5: Comparison of system measures against simulation outputs

\begin{tabular}{lrrrr}
\hline Measure & System mean & Lower bound & Upper bound & Simulation output \\
\hline Total time until labelled (h) & 17.67 & 17.20 & 18.13 & 17.44 \\
Same-day despatched orders (\%) & 95.55 & N/A & N/A & 94.97 \\
Time waiting before picking (h) & 10.89 & 10.65 & 11.12 & 10.94 \\
Time waiting to be packed (h) & 0.39 & 0.36 & 0.43 & 0.39 \\
Total labelling duration (h) & 1.56 & 1.450 & 1.61 & 1.59 \\
Trolleys/size (\%) Small & 41.82 & N/A & N/A & 41.59 \\
$\quad$ Medium & 23.22 & N/A & N/A & 23.64 \\
Large & 34.96 & N/A & N/A & 34.78 \\
Number of orders despatched & 13815 & N/A & N/A & 13741 \\
\hline
\end{tabular}

The most important measure used in this validation technique was the total time an order spends in the 
warehouse from the moment it is received to the moment it is labelled. The simulation mean was just $1 \%$ smaller than the system mean for this measure. Another important measure the company is using is "sameday despatch". An order is considered despatched on the same day if it leaves the warehouse on the same day it was received (as long as it was received before $3 \mathrm{pm}$ ). The next four measures are about parameters that could not be determined by an input distribution such as waiting times in queues and number of trolleys used (rows 3-7). Finally, we compared the output of the simulation model against the output of the real system, which had only a $0.5 \%$ difference. 